\title{
Marketing Social e Extensão Universitária: As Ações da Uri Cerro Largo o Contexto Social
}

\author{
Roberto Schuster Ajala ${ }^{1}$ \\ Raquel Borghetti ${ }^{2}$ \\ Luciana Scherer ${ }^{3}$
}

Resumo: A Universidade Regional Integrada do Alto Uruguai e das Missões (URI) completou, no ano de 2017, seus 25 anos no município de Cerro Largo, tendo como missão institucional, a formação de profissionais baseados na ética e no comprometimento com a comunidade. Sob essa orientação da missão da universidade, a disciplina de Fundamentos de Marketing do curso de Administração, na qual são desenvolvidos conceitos de Marketing Social, dá sustentação para algumas ações que tentam responder aos movimentos da sociedade, que passa a exigir um novo papel das organizações. Papel este que busca ir além da questão da geração de lucros e empregos e que embasa as discussões sobre Marketing e Responsabilidade Social das Organizações. Assim surgem novas expectativas sobre as atuações organizacionais e universitárias sob o mote da noção de Responsabilidade Social Universitária. Em discussão análoga, uma das funções das universidades passa a ser considerada terreno fértil para as ações que perfazem um elo entre essas instituições e a sociedade, e portanto, a relação da extensão universitária como reflexo da relação entre universidade e sociedade. Com esse posicionamento epistemológico se constrói o estudo com o objetivo de apresentar um relato de experiência dessa atuação de extensão universitária e responsabilidade social executadas por discentes, docentes e técnicos-administrativos desta instituição. Tais ações são conduzidas pelos pressupostos teóricos da Extensão Universitária, da Responsabilidade Social e Responsabilidade Social Universitária, com vistas à construção de um processo educativo para a intervenção no desenvolvimento de Cerro Largo e região adjacente.

Palavras chave: Extensão Universitária. Marketing Social. Responsabilidade Social Universitária.

Abstract: The Universidade Regional Integrada do Alto Uruguai e das Missões (URI) completed its 25 years in the municipality of Cerro Largo in 2017, with the institutional mission of training professionals based on ethics and commitment to the community. Under the guidance of the University's mission, the Marketing Fundamentals course in Management, in which Social Marketing concepts are developed, provides support for some actions that attempt to respond to the society's movements, which require a new role for organizations, that extrapolate the generation of profits and jobs, and which give rise to the discussions on

\footnotetext{
${ }^{1}$ Mestre em Gestão Estratégia das Organizações (URI). Professor na Universidade Regional do Alto Uruguai e das Missões - campus Cerro Largo. roberto@uricl.com.br

${ }^{2}$ Mestra em Desenvolvimento (UNIJUÍ). Professora na Universidade Regional do Alto Uruguai e das Missões campus Cerro Largo. raquelborghetti@ fundiçãoborghetti.com.br

${ }^{3}$ Mestra em Ciências Sociais (PUCRS). Professora na Universidade Regional do Alto Uruguai e das Missões campus Cerro Largo. lucianascherer@yahoo.com.br
} 
Marketing and Social Responsibility of Organizations. Thus new expectations arise on the organizational and university actions, under the motto of the notion of University Social Responsibility. In an analogous discussion, one of the functions of universities becomes fertile ground for actions that form a link between these institutions and society, and therefore, the relation of university extension, as a reflection of the relationship between university and society. With this epistemological positioning, the study is built with the objective of presenting an experience report of this performance of university extension and social responsibility carried out by students, teachers and technical-administrative personnel of this institution. These actions are driven by the theoretical assumptions of University Extension, Social Responsibility and University Social Responsibility, with a view to constructing an educational process for intervention in the development of Cerro Largo and its surrounding region.

Key words: University Extension. Social Marketing. University Social Responsibility.

\section{INTRODUÇÃO}

Ao longo do tempo as relações entre organizações e sociedade vêm se transformando e alterando as demandas recíprocas. Em meio às pressões impostas às organizações a responsabilidade social tornou-se fundamental para o desenvolvimento e crescimento das organizações, visto que a sociedade exige uma postura ética e social das mesmas. Neste contexto de cobranças e pressões externas por práticas sociais que evidenciem a responsabilidade social das organizações, inserem-se as Instituições de Ensino Superior que são organizações focadas na educação e formação de seres humanos. Como formadoras de profissionais, as IES têm importante papel na formação dos seus alunos em contextos que extrapolam as habilidades e competências técnico-científicas, abordando também conhecimentos sobre a comunidade, questões sociais, ambientais, culturais e de postura ética e engajada. Sendo assim cabe às universidades trazerem ao conhecimento dos seus alunos os problemas da sociedade em geral e de forma particular da sua região ou cidade para que através destes possam ser criadas soluções viáveis e inovadoras, que tenham responsabilidade com a sociedade de forma geral.

A Universidade Regional do Alto Uruguai e Missões - Extensão Cerro Largo completa no ano de 2017, seus 25 anos no município de Cerro Largo, tendo como missão institucional, a formação de profissionais baseados na ética e no comprometimento com a comunidade, e é caracterizada desde a sua concepção, por ter definido como um dos princípios de sua atuação a relação estreita com a comunidade local. Isto significa hoje, uma necessidade clara de avançar

Revista Extensão em Foco, nº 17, Out./ Dez. (2018), p. 01 - 17. 
nas ações de extensão, promovendo uma integração entre os conhecimentos acadêmicos, as problemáticas locais e a participação na comunidade.

Neste sentido, a abordagem de marketing social neste artigo é construída a partir da integração desse conceito com a responsabilidade social e a extensão universitária, levando em consideração os benefícios para a IES (e seus participantes discentes e docentes) e para a sociedade. Por meio da extensão universitária, que é alicerçada no diálogo, é possível realizar o processo de interação social, ou seja, o empoderamento das representações coletivas, por meio da combinação entre a teoria e a prática do marketing social. Como referencial de análise seguese o arcabouço teórico de Vaz (1995) e Kotler e Zaltman (1971) que apresentam a modalidade como ações institucionais com objetivo de atenuar problemas sociais ligados a higiene, saúde pública, trabalho, educação, transportes ou nutrição e ainda, aquela capaz de proporcionar mudanças sociais desejadas.

A experiência relatada faz-se a partir de um conjunto de três projetos realizados no âmbito da extensão universitária com ações de responsabilidade social na URI - Cerro Largo: o Natal Solidário, a Campanha de Doação de Sangue e a Campanha Criança Vestida, Criança Feliz.

As referidas ações são desenvolvidas no âmbito da disciplina Fundamentos de Marketing do $3^{\circ}$ semestre do Curso de Administração da URI, quando são abordados os aspectos teórico-metodológicos de Marketing Social. Nesta etapa esses aspectos surgem, em um primeiro momento, como ação de ensino e, posteriormente, são ampliados como ações de extensão.

O objetivo desse artigo é apresentar as ações a partir do referencial teórico que posiciona a extensão universitária como ações de marketing social por meio da responsabilidade social.

Este artigo é relevante no contexto do desenvolvimento local por três razões principais. A primeira, diz respeito à sistematização de um trabalho que, embora embrionário, serve de referência para a formação de pessoas preocupadas com a problemática socioeconômica da comunidade em que estão envolvidos. A segunda é a apresentação de uma experiência que está sendo construída e que a partir disso pode servir de inspiração para novos estudos e novas práticas de intervenção na realidade concreta, o que atende às atuais características do processo de ensino-aprendizagem de um profissional com formação ética. E a terceira, é a preocupação da área de ensino, pesquisa e extensão em Administração e Contabilidade em difundir casos e

Revista Extensão em Foco, nº 17, Out./ Dez. (2018), p. 01 - 17. 
metodologias que possuem perspectivas metodológicas e epistemológicas coerentes com a realidade do docente, do discente e demais integrantes da instituição de ensino.

As opções metodológicas são as próprias das ciências sociais aplicadas, de estilo qualitativo com a realização de um relato de experiência, o qual se caracteriza como sendo obrigatório a demonstração de uma experiência prática para maior compreensão e fundamentação de uma teoria (CESED, S/D. p. 1).

A estrutura do estudo será apresentada em três partes, além da introdução e das considerações finais. Na primeira, faz-se a contextualização da URI -Cerro Largo, com seu histórico de formação e características atuais. A segunda traz os referenciais de análise: responsabilidade social, extensão universitária e responsabilidade social universitária. $\mathrm{Na}$ sequência apresentam-se as experiências concretas das três ações desenvolvidas pela comunidade acadêmica da URI Cerro Largo.

Espera-se com esse estudo contribuir-se com a construção de conhecimento e trocas de saberes baseados nas discussões teórico-epistemológicas da extensão universitária como instrumento de consolidação de ações práticas de marketing social e de responsabilidade social.

\section{URI CERRO LARGO: HISTÓRICO E CARACTERÍSTICAS ATUAIS}

A Universidade Regional Integrada do Alto Uruguai e Missões (URI) é uma instituição integrada, regional, comunitária e multicâmpus, reconhecida pela Portaria no 708 de 19 de maio de 1992, e tem como missão "Formar pessoal ético e competente, capaz de construir o conhecimento, promover a cultura, o intercâmbio, a fim de desenvolver a consciência coletiva na busca contínua da valorização e solidariedade humana". A URI - Extensão de Cerro Largo, está inserida no município de Cerro Largo e região desde o reconhecimento da Universidade e identifica-se como uma instituição comprometida com o desenvolvimento e o futuro da região onde atua, reconhecendo a necessidade de preparar pessoas para enfrentar os desafios na condução de sua missão institucional, planejando suas ações de modo a atender as necessidades educacionais.

A Unidade de Cerro Largo contribui com a inclusão social e com o desenvolvimento econômico e social da região pela proposta de um ensino diferenciado. O seu centro de interesse e busca permanente converge para o ensino superior caracterizado pelo compromisso de entregar à comunidade, egressos com condições de atuar de forma eficaz e a partir de uma Revista Extensão em Foco, nº 17, Out./ Dez. (2018), p. 01 - 17. 
formação sólida, atual e humana, nas demandas das organizações e na transformação da realidade social por intermédio do uso de seus conhecimentos adquiridos.

A URI traz em sua bagagem o papel de impulsionadora do desenvolvimento social e regional, pois sendo uma Universidade comunitária, cumpre sua missão, também, como fator de mudança cultural imprescindível diante deste mundo cada vez mais globalizado, na área econômica e cultural. Assim a Universidade assume o papel de preparar novos profissionais gerando e difundindo conhecimento, informação e tecnologia para os setores políticoadministrativo de toda a comunidade.

Neste contexto, vemos a URI buscando cumprir seu papel social na comunidade em que está inserida, dando ênfase aos seus projetos de extensão, pois a extensão é vista como uma forma de interação universidade-comunidade, num processo educativo, cultural e científico que articula ensino e pesquisa de forma harmônica e estabelece ação transformadora na relação de troca de informações e saberes. Dessa forma, as políticas de extensão na URI, envolvem e criam condições para a formação de cidadãos capazes de integrarem-se às ações que promovam o desenvolvimento sustentável da comunidade, difundindo e transferindo conhecimento.

\section{MARKETING SOCIAL， RESPONSABILIDADE SOCIAL， EXTENSÃO E RESPONSABILIDADE SOCIAL UNIVERSITÁRIA: CONCEITOS E INTER- RELAÇÕES}

Os referenciais de análise utilizados nesse artigo estão alicerçados em uma perspectiva que vai além da epistemologia sobre a atuação da universidade, e que foca na atuação que extrapola a formação profissional, ou seja, a formação do profissional na sua concepção de ator integrante de uma comunidade.

Nesse sentido, recorre-se à indissociabilidade entre ensino, pesquisa e extensão referida na Constituição Federal de 1988, como um princípio a ser seguido, já que no artigo 207, estabelece-se que "as universidades gozam de autonomia didático-científica, administrativa e de gestão, e obedecerão ao princípio da indissociabilidade entre ensino, pesquisa e extensão" (BRASIL, 1998). Esse princípio, hoje, coloca-se como um requisito para as instituições serem consideradas universidades (MOITA; ANDRADE, 2013) e, portanto pode ser um ponto de partida para posicionar as funções da universidade no contexto atual. Sendo esse tripé apontado como caminho elementar para a construção de uma universidade de bom nível acadêmico Revista Extensão em Foco, nº 17, Out./ Dez. (2018), p. 01 - 17. 
(PUCCI, 1991), o mesmo deve ser integrado, nunca compartimentado, e as três funções devem ser equivalentes e sempre merecem igualdade de tratamento por parte das instituições de ensino superior (RAYS, 2003; MOITA; ANDRADE, 2013).

O entendimento sobre extensão universitária, conforme estabelecido no I Encontro Nacional de Pró-Reitores de Extensão em 1987, foi corroborado no Plano Nacional de Extensão Universitária:

\begin{abstract}
A Extensão Universitária é o processo educativo, cultural e científico que articula o Ensino e a Pesquisa de forma indissociável e viabiliza a relação transformadora entre Universidade e Sociedade. [...] é uma via de mão-dupla, com trânsito assegurado à comunidade acadêmica, que encontrará, na sociedade, a oportunidade de elaboração da práxis de um conhecimento acadêmico. No retorno à Universidade, docentes e discentes trarão um aprendizado que, submetido à reflexão teórica, será acrescido àquele conhecimento. Esse fluxo, que estabelece a troca de saberes sistematizados, acadêmico e popular, terá como consequências a produção do conhecimento resultante do confronto com a realidade brasileira e regional, a democratização do conhecimento acadêmico e a participação efetiva da comunidade na atuação da Universidade. (FORPROEX, 2000, p. 5).
\end{abstract}

A extensão universitária, se por muito tempo fora colocada como uma função menos importante passa, neste contexto a ser integrante de todo um processo que possibilita a relação da universidade com uma realidade concreta, com os saberes e situações que se encontram na sociedade e não necessariamente nas salas de aula e laboratórios, mas também percebendo o contexto social ao qual a universidade está inserida. Por meio do referido tripé (ensinopesquisa-extensão) é possível articular pesquisa, ensino e extensão num único processo de aplicação de saberes e de relação com a sociedade, já que como função acadêmica da universidade, a extensão visa integrar os saberes gerados nas práticas para colocar-se como um elo entre a universidade e a comunidade, e vem transitar como uma ferramenta para propiciar um reconhecimento de que a universidade tem uma função social que vai além das salas de aula e laboratórios. A extensão, se colocada ao lado e no mesmo patamar do ensino e da pesquisa, possibilita democratizar a universidade, colocando-a em sintonia com a comunidade e com a realidade. Nesse sentido, surge a tendência de repensar a extensão universitária enquanto atividade acadêmica para colocá-la ao lado do ensino e da pesquisa como meio para democratizar o conhecimento produzido e ensinado na universidade e ao mesmo tempo possibilitar que esta universidade atenda às demandas mais urgentes da população, na crítica e na reconstrução de uma sociedade mais justa.

Revista Extensão em Foco, nº 17, Out./ Dez. (2018), p. 01 - 17. 
Sob essa ótica da extensão universitária, voltada para a coletividade, surge um entendimento relacionado com o marketing social e a responsabilidade social, o segundo e o terceiro referenciais abordados, respectivamente, nesse estudo. Esses são conceitos que vem se desenvolvendo nos campos da administração e da gestão, das ciências políticas e da economia.

A concepção de Estado mínimo, na qual se tem a doutrina da descentralização das políticas sociais e, ao mesmo tempo, a transferência de responsabilidade para organizações da sociedade civil em relação ao surgimento da responsabilidade social como um paradigma de atuação de organizações, sejam públicas ou privadas para o engajamento da sociedade como um todo para a transformação social.

Com o Estado mínimo, baseado em economia de mercado, surgem, talvez como reação, algumas pressões impostas às empresas, no sentido de que seu papel deve ir além da obrigação de geração de lucro para os acionistas, oferta de empregos e cumprimento com as obrigações legais vigentes. Nesse sentido, as empresas deveriam promover práticas voltadas ao ambiente, natural e humano, e saber da necessidade de ir além daquele seu papel básico de geração de lucros, levando em conta também os resultados e impactos das ações e atividades geradas na própria organização, para seus membros, para grupos de interesse com os quais se relacionam e na cidadania coletiva (PERNALETE; ORTEGA, 2010). A partir dessas pressões, e das novas demandas da sociedade para com as empresas, o marketing e a responsabilidade social tornaram-se fundamentais para o desenvolvimento e crescimento das organizações visto que a sociedade, de certa forma, espera delas uma postura ética e socialmente integrada com as comunidades.

Em relação ao marketing social, têm-se em Kotler e Zaltman (1971 p.5) a ideia de que esse conceito se caracteriza como o desenho, planejamento e controle de programas para influenciar a aceitação de ideias sociais envolvendo considerações de planejamento de produto, comunicação, preço, distribuição e pesquisa de mercado. Outra concepção importante e ampliada do marketing social orienta as ações nesse contexto:

\footnotetext{
A modalidade de ação mercadológica institucional que tem como objetivo principal atenuar ou eliminar os problemas sociais, as carências da sociedade relacionadas principalmente às questões de higiene e saúde pública, de trabalho, educação, habitação, transportes e nutrição (VAZ, 1995, p. 280).
}

Outra ideia importante para esse estudo é a encontrada em Kotler e Roberto (1992), quando os autores revisam o conceito proposto anteriormente afirmando que o marketing social Revista Extensão em Foco, nº 17, Out./ Dez. (2018), p. 01 - 17. 
objetiva uma mudança de comportamento. Embora o entendimento sobre marketing e responsabilidade social tenha se desenvolvido a partir do argumento de que o papel das organizações deve ir além da geração de lucros e empregos, no início do século XX, esse "ir além" esteve restrito a noção de filantropia (TENÓRIO, 2006). Mesmo que essa noção seja limitada a doação ou ajuda, ela serve como uma concepção embrionária do que se tem no entendimento da responsabilidade social na atualidade:

\begin{abstract}
A forma de gestão que se define pela relação ética e transparente da empresa com todos os públicos com os quais ela se relaciona e pelo estabelecimento de metas empresariais compatíveis com o desenvolvimento sustentável da sociedade, preservando recursos ambientais e culturais para gerações futuras, respeitando a diversidade e a redução das desigualdades sociais (ETHOS, 2011, n.p.).
\end{abstract}

Dessa forma, parece consenso para diversos autores a noção de que a responsabilidade social vai além do filantropismo, já que pode ser entendida como a ideia de que uma organização deveria olhar além de seus próprios interesses e dar uma contribuição para a sociedade (NICHELS e WOODS, 1999); como o compromisso da organização em relação a sociedade, expressa por atitudes que nela criem um efeito positivo (ASHLEY, 2002); como o grau de obrigações que uma organização assume por meio de ações que protejam e melhorem o bem-estar da sociedade à medida que procura atingir seus próprios interesses (CHIAVENATO; ARÃO, 2004) ou como aquela fundamentada no compromisso pessoal e/ou organizacional para com o desenvolvimento sustentável, levando em conta a ética (GONZÁLEZ, 2009). Para Churchil e Peter (2000), a aceitação da responsabilidade social baseia-se, em parte, na visão de que ela interessa para a empresa, mas também é uma questão de ética.

Neste cenário de mudanças nas relações das expectativas da sociedade e pressões externas por práticas sociais que evidenciem a responsabilidade social das organizações, estão inseridas também as Instituições de Ensino Superior (IES), organizações focadas na educação e formação acadêmica, profissional e na produção do conhecimento. Para Severino (2008), é na universidade que se forma o capital humano e, portanto, não se deve deixar de lado a formação humana integrada à sociedade. Sob esse posicionamento, surge o terceiro referencial de análise que norteia esse estudo, a Responsabilidade Social Universitária, hoje requisito inquestionável tanto em IES públicas quanto privadas (ASHLEY; FERREIRA, REIS, 2006) a

Revista Extensão em Foco, nº 17, Out./ Dez. (2018), p. 01 - 17. 
qual congrega a partir de uma visão integrada, sistêmica e holística, a articulação de departamentos e setores, em um projeto de atuação social de princípios éticos e de desenvolvimento social baseado na promoção da equidade e da sustentabilidade, visando à produção e transmissão de saberes, de responsabilidade e à formação de profissionais cidadãos igualmente responsáveis (VALLAEYS, 2006).

A responsabilidade social pode ser entendida como a:

Capacidade que possui a universidade de difundir e colocar em prática um conjunto de princípios e valores, gerais e específicos, por meio de quatro processos considerados chaves: gestão, docência, pesquisa e extensão universitária, respondendo socialmente desta forma perante a própria comunidade universitária e o país onde está inserida (JIMÉNEZ et al. 2006, p. 15).

A Responsabilidade Social Universitária transcende, portanto, o espaço físico da universidade, assumindo um protagonismo crítico, responsável e de caráter ético da instituição para solucionar ou, no mínimo, auxiliar na redução de problemas sociais no ambiente em que atua. Assim, no debate acerca da Responsabilidade Social Universitária - aqui entendida sob a epistemologia da Responsabilidade Social no contexto específico das IES, as ações de extensão universitária assumem um papel significativo (RIBEIRO, 2012), já que o elo, o diálogo e a relação entre IES e sociedade pode ser colocado por meio da elaboração e execução de projetos e programas de alcance social, tanto no âmbito da instituição quanto na comunidade em que está inserida. É sob esse arcabouço teórico que são desenvolvidas as ações de Responsabilidade Social na URI Cerro Largo relatadas nesse estudo, visando acima de tudo, extrapolar a formação acadêmica, profissional e a produção do conhecimento de seu corpo discente, para além disso, formar um capital humano consciente e comprometido com as questões sociais, culturais, políticas e econômicas tanto no ambiente interno como externo da instituição.

\section{A URI CERRO LARGO E AS AÇÕES DE MARKETING SOCIAL E EXTENSÃo UNIVERSITÁRIA}

As ações relatadas nesse estudo são aquelas realizadas a partir do entendimento da necessidade de envolvimento da URI na comunidade em que está inserida. Partindo do tripé das funções da universidade: ensino-pesquisa-extensão, elaboram-se algumas ações de

Revista Extensão em Foco, nº 17, Out./ Dez. (2018), p. 01 - 17. 
intervenção na realidade concreta. Nesse contexto, destacam-se três ações importantes: o Natal Solidário, a Mobilização para Doação de Sangue e a Campanha Criança Feliz, Criança Vestida, as quais serão relatadas a seguir.

As referidas ações são desenvolvidas no âmbito da disciplina Fundamentos de Marketing, do $3^{\circ}$ semestre do Curso de Administração da URI, quando são abordados os aspectos teórico-metodológicos de Marketing Social, portanto, surge em um primeiro momento como uma ação de ensino e posteriormente como ações de extensão envolvendo toda a comunidade acadêmica e visando estreitar o relacionamento com a comunidade externa. $\mathrm{O}$ caminho metodológico percorrido para a elaboração das três ações acima destacadas consistiu nas seguintes fases:

- Leituras sobre Responsabilidade Social e Marketing Social;

- Realização de um seminário no qual os alunos apresentaram conhecimentos teórico-metodológicos e experiências concretas de ações de Responsabilidade Social e Marketing Social;

- Rodada de um Braimstorming com ideias sobre possíveis temáticas sociais;

- Escolha da ação a ser desenvolvida;

- Definição de equipes que seriam responsáveis por cada uma das etapas integrantes do projeto: elaboração do projeto, apresentação para a direção, comunicação, divulgação e marketing - da ação, operacionalização das arrecadações e operacionalização das distribuições.

- Acompanhamento e gestão da ação com os papéis definidos até a fase de finalização.

A seguir, apresentam-se três ações de Marketing e Responsabilidade Social desenvolvidas no âmbito da URI- Cerro Largo.

\section{O NATAL SOLIDÁRIO}

O Natal Solidário é uma ação desenvolvida desde 2014. A partir do conhecimento, pelos alunos, sobre a missão da URI e sobre as funções de uma universidade, surge a entendimento da necessidade de extrapolar a sala de aula e inserir a realidade concreta nas ações didáticas Revista Extensão em Foco, nº 17, Out./ Dez. (2018), p. 01 - 17. 
desenvolvidas pelos docentes em suas disciplinas, já que muito da formação ética e comprometida com a comunidade passa por esse tipo de envolvimento com questões comunitárias, sociais e ambientais.

Assim surgiu a ideia de realizar uma ação para distribuição de brinquedos e doces arrecadados para crianças carentes no dia 24 de dezembro, véspera de Natal. Esses brinquedos e doces figuravam como os presentes de Natal, que foram arrecadados pelos professores, funcionários e atores da comunidade, sendo depois embalados com papel coloridos e fitas, e distribuídos pelos próprios acadêmicos e por um Papai Noel em comunidades carentes do município de Cerro Largo.

A campanha já está na sua $4^{\text {a }}$ edição, ela foi realizada nos anos de 2014, 2015 e 2016 e os preparativos para o Natal 2017 já foram iniciados. Nesse período dessas edições, já foram arrecadados e doados aproximadamente 665 brinquedos e 85 cestas de doces.

Figura 1 - Distribuição de presentes na campanha Natal Solidário.
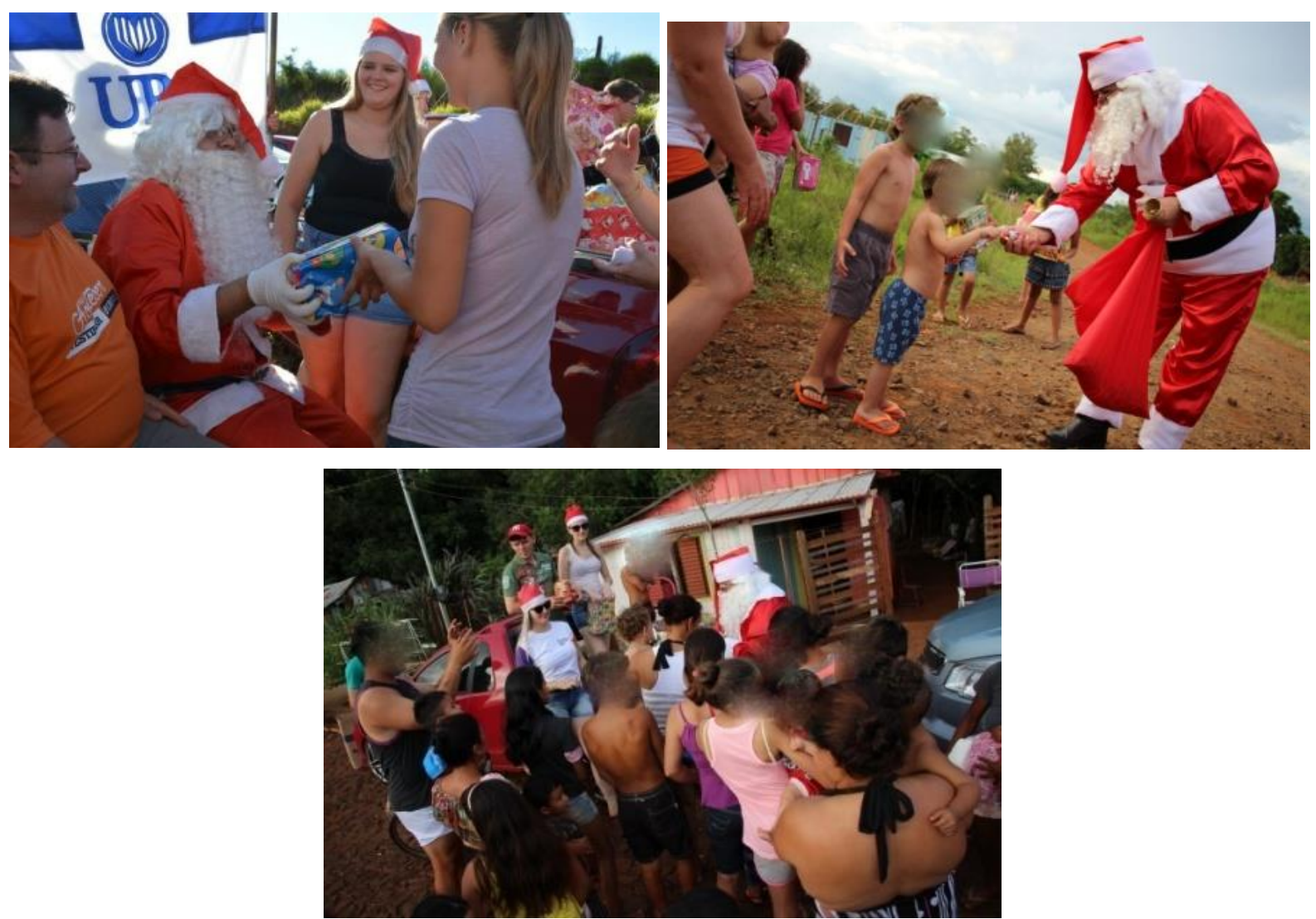

Fonte: dados da pesquisa (2017).

\section{CAMPANHA DE DOAÇÃO DE SANGUE}

Revista Extensão em Foco, nº 17, Out./ Dez. (2018), p. 01 - 17. 
A campanha de Doação de Sangue foi elaborada em 2015 e também teve início durante a disciplina do $3^{\circ}$ semestre, a partir dos estudos sobre responsabilidade social e marketing social. Após a estruturação do projeto, foram realizadas ações de sensibilização em 2016, com apresentações no auditório da universidade para todos os alunos dos Cursos de Ciências Contábeis e de Administração e também foram realizadas visitas às salas de aula para reforçar a campanha e realizar o cadastramento de 70 doadores (com a relação do tipo sanguíneo de cada doador cadastrado). Foram também apresentados dados sobre a problemática da doação de sangue e sobre a importância do engajamento da comunidade acadêmica em questões externas.

Figura 2 - Materiais informativos e de divulgação.
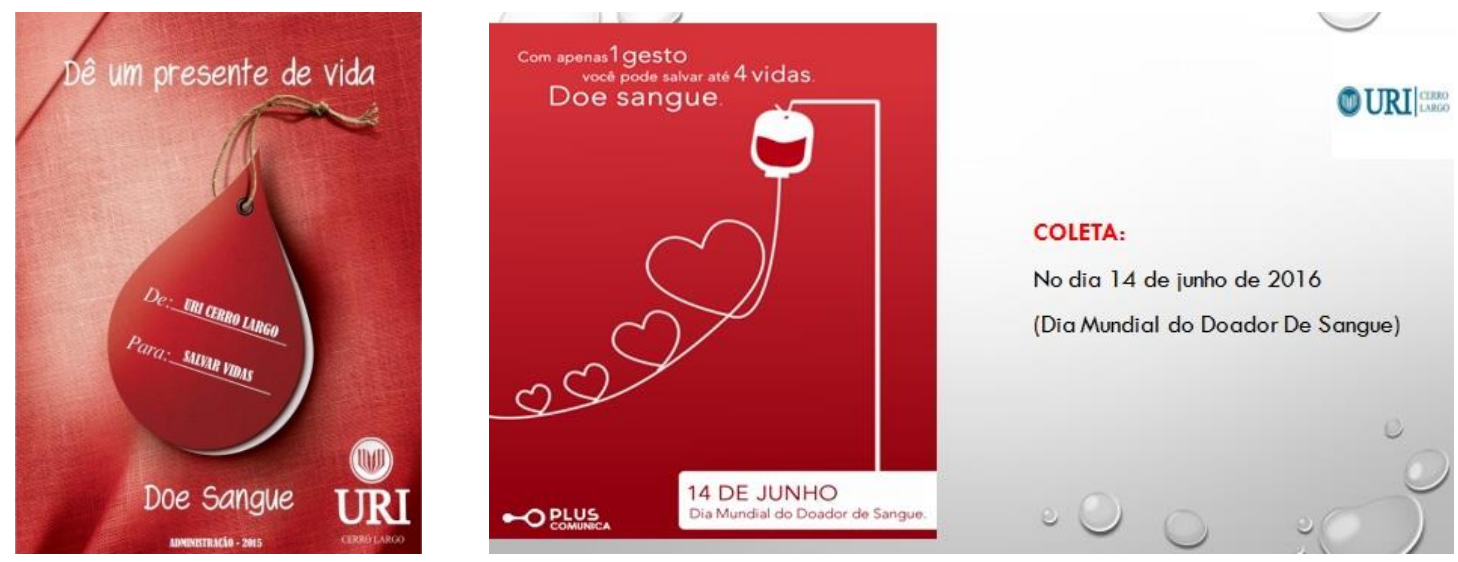

Fonte: dados da pesquisa (2017).

Figura 3 - Alunos na ação de doação.
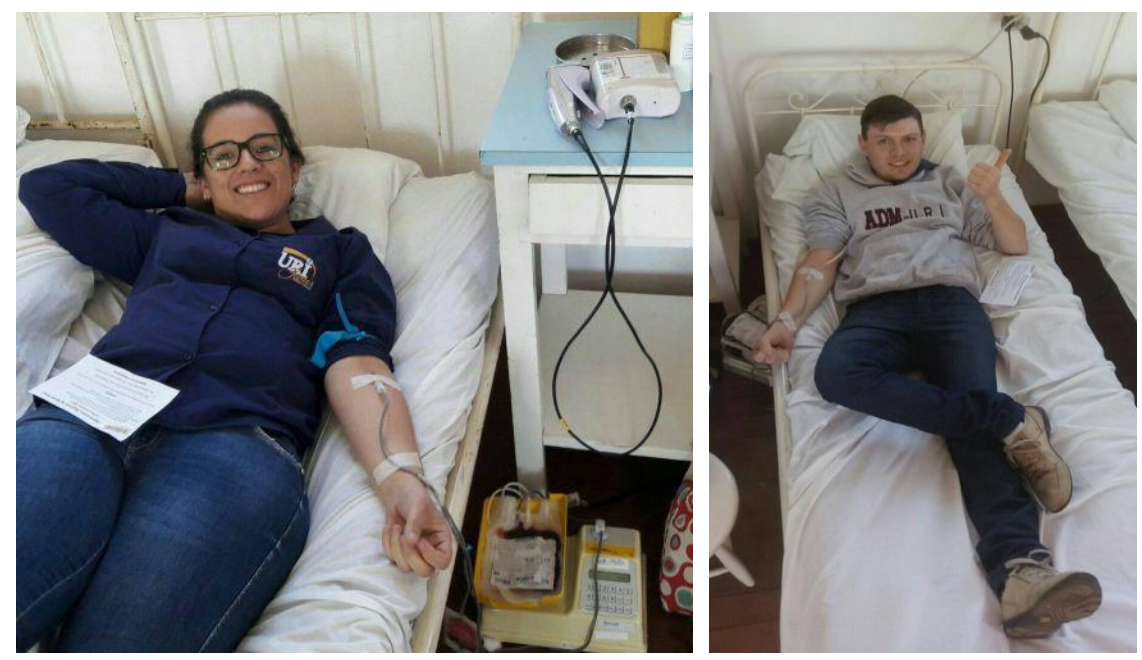

Revista Extensão em Foco, nº 17, Out./ Dez. (2018), p. 01 - 17. 
São parceiros diretos desse projeto o Hemocentro Regional de Santa Rosa (HEMOSAR) e a Associação Hospitalar de Caridade Serro Azul (AHCASA), os quais desempenham além do papel de divulgadores sobre a importância da ação, o papel de informar para a Universidade sempre que houver necessidade de doação de algum tipo específico de sangue, ou mesmo quando os níveis de estoque de sangue cheguarem a níveis abaixo do necessário para o funcionamento do sistema.

\section{CAMPANHA CRIANÇA VESTIDA, CRIANÇA FELIZ}

A Campanha Criança Vestida, Criança Feliz é a ação de marketing e responsabilidade social que está sendo realizada nesse ano de 2017. Após o caminho metodológico desenvolvido para essas ações já no ano de 2015 e replicados em 2016 e 2017, o escopo da ação voltou-se novamente para o público infantil por meio da doação de roupas e calçados para crianças de até 10 anos de idade.

Como estratégia de sensibilização, os alunos responsáveis pela ação visitaram todas as salas de aula e direcionaram-se também aos professores em seus gabinetes de trabalho, apresentando a campanha e solicitando que todos participassem com doações e também com divulgação para sua rede de relacionamento pessoal externa à URI. Foram também disponibilizadas caixas de coletas no saguão de entrada e na área próxima à cantina.

Figura 4 - Logomarca de divulgação.

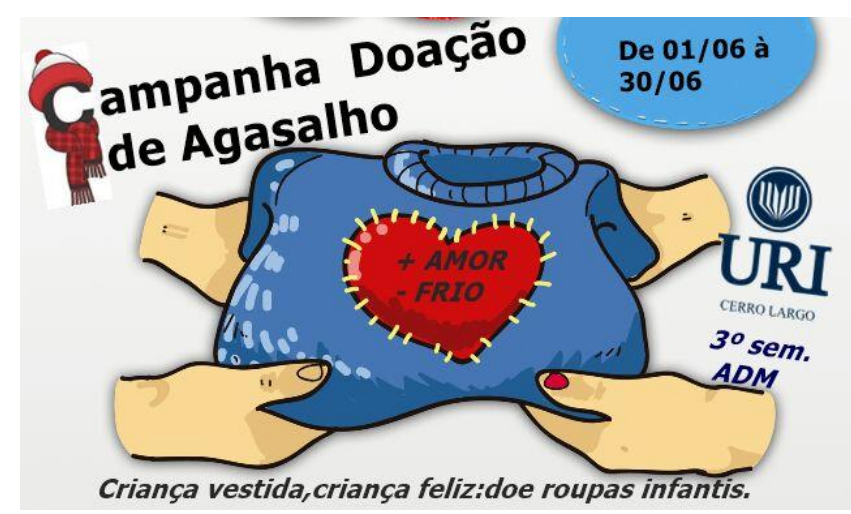

Fonte: dados da pesquisa (2017).

Revista Extensão em Foco, n 17, Out./ Dez. (2018), p. 01 - 17. 
Foram arrecadadas 710 peças, as quais foram doadas para a Assistência Social do município de Cerro Largo pelos alunos do $3^{\circ}$ semestre de Administração, conforme ilustrado na figura 5.

Figura 5 - Alunos e Professores realizando a doação.

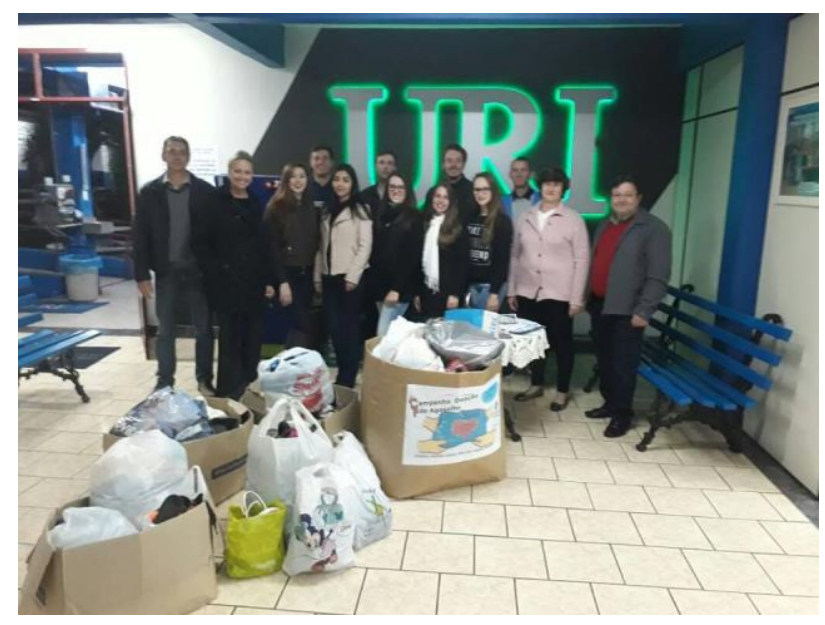

Fonte: dados da pesquisa (2017).

Importante salientar que as campanhas de responsabilidade social da URI Cerro Largo complementam-se, entre si, e ainda articulam o tripé do ensino-pesquisa-extensão. As ações como o Natal Solidário (iniciada em 2014, mas que segue sendo realizada em 2015 e 2016), Doação de Sangue (instituída em 2016), Criança bem Vestida, Criança Feliz (realizadas em 2017) foram desenvolvidas em anos diferentes, em turmas diferentes e possuem a característica de continuidade ao longo de todos os semestres. Embora ainda bastante recentes, demonstram uma capacidade que combina teoria com prática, formação técnico-científica com um olhar para as questões sociais e o envolvimento com a comunidade.

\section{CONSIDERAÇÕES FINAIS}

Fazer parte de uma universidade, seja como docente, seja como gestor, funcionário ou aluno, é algo que desperta o interesse por melhor compreender a dinâmica desta instituição no desempenho de suas funções básicas e seu papel principal na produção e difusão do conhecimento para o desenvolvimento de uma determinada sociedade. A URI Cerro Largo, às vésperas de completar 25 anos de atuação no município de Cerro Largo - RS, compreende a

Revista Extensão em Foco, nº 17, Out./ Dez. (2018), p. 01 - 17. 
importância do tripé formado pelo ensino-pesquisa-extensão, como forma imprescindível para o planejamento, desenvolvimento e avaliação das atividades curriculares e estratégicas que pretendem tomar o conceito como princípio norteador das práticas cotidianas na instituição.

A missão de uma Universidade está pautada na construção, projeção e difusão do conhecimento, funcionando como um instrumental de entendimentos, compreensão e expressão dos movimentos sociais, políticos, econômicos e culturais produzidos pelo Estado, mercado e sociedade. Porém, como detentora de saberes e de conhecimentos, entende-se que há ainda uma missão que vai além do dever de expor para a sociedade o surgimento de novas abordagens para compreensão de fenômenos organizacionais, ou seja, além de agregar os seus conhecimentos na sociedade, é preciso inserir a sociedade e suas problemáticas nos seus processos.

Um relato de experiências é uma forma contemporânea de produção, difusão do conhecimento e divulgação de saberes, onde os atores envolvidos podem expressar suas vivências, dificuldades e desafios, valorizando as diferentes formas de saber, integrando conhecimento acadêmico-científico com a produção de conhecimento em toda a sociedade. Esse é o contexto de apresentação deste trabalho: dividir conhecimento sobre as ações de extensão aliado ao conhecimento tácito e empírico do público envolvido. Essa rede de atuação conjunta propicia o desenvolvimento de experiências.

O marketing social tratado como elemento teórico na disciplina de Fundamentos do Marketing do curso de Administração, a partir das experiências relatadas, inter-relaciona-se com ações concretas de responsabilidade social, extensão e responsabilidade social universitária. Professores e alunos participam de uma atividade prática que vai muito além do aprendizado em sala de aula. Há, a partir do exposto, uma formação humana, ética e comprometida com a comunidade. Essas iniciativas marcam os atores envolvidos e certamente colaboram para o papel da universidade na comunidade.

As ações de extensão aqui relatadas, demonstram o comprometimento do público interno da URI Cerro Largo para com o público externo. Para os discentes, o objetivo maior é a consolidação de uma postura cidadã, pautada na criação de capital humano que extrapola a necessidade de formação científica. A partir dessas ações relatadas, percebe-se que projetos de extensão realizados oferecem formação além dos limites da sala de aula, transitando por inúmeras práticas interdisciplinares focadas no relacionamento e na discussão sobre questões pertinentes a sociedade. Evidencia-se, portanto, que a URI Cerro Largo, ao estimular os projetos Revista Extensão em Foco, nº 17, Out./ Dez. (2018), p. 01 - 17. 
apresentados nesse relato de experiência, cumpre e operacionaliza seu papel institucional de indissociabilidade entre o ensino, pesquisa e extensão, conforme previsto na Constituição brasileira de 1988 em seu artigo 207, “(...) obedecerão ao princípio da indissociabilidade entre ensino, pesquisa e extensão", princípio reforçado por Pucci (1991), Rays (2003) e Moita e Andrade (2013).

\section{REFERÊNCIAS}

ASHELY, P. Ética e Responsabilidade Social nos Negócios, São Paulo: Saraiva, 2002.

ASHLEY, P.; FERREIRA, R.; REIS, H. Sistema Nacional de Avaliação da Educação Superior: Oportunidades para a responsabilidade social na gestão estratégica de instituições de ensino superior. Revistas Gerenciais, São Paulo, v. 5, p. 23-35, 2006.

BRASIL. Constituição da República Federativa do Brasil. Brasília, DF: Senado Federal, 1998.

CENTRO DE ENSINO SUPERIOR E DESNVOLVIMENTO - CESED. (SD) Relato de Experiência. Disponível em: http://www.cesed.br/portal/documentos/ posgraduacao/roteiroelaboracaorelatoexperiencia.pdf

CHIAVENATO, I; ARÃO, S. Planejamento Estratégico: Fundamentos e Aplicações. Rio de Janeiro: Elsevier, 2004.

CHURCHILL, G. A.; PETER, J. Marketing: criando valor para os clientes. São Paulo: Saraiva, 2000.

ETHOS, Instituto. O que é Responsabilidade Social Empresarial. Disponível em: $\langle\underline{w w w}$.ethos.org.br/EthosWeb/pt/29/oqueerse/oqueerse.aspx $>$ Acesso em: 11 de Agosto de 2011.

FORPROEX. FÓRUM DE PRÓ-REITORES DE EXTENSÃO DAS UNIVERSIDADES PÚBLICAS BRASILEIRAS E SESU/MEC. Plano Nacional de Extensão Universitária. Ilhéus: Editus, 2000.

GONZALEZ, C. Ética e responsabilidade social. Cadernos da Escola Judicial do TRT da 4ª Região, Porto Alegre, v.1, n.2, p.17-23, jul. / dez, 2009.

JIMÉNEZ, M et al. Responsabilidade universitária: uma experiência inovadora na América Latina. Estudos, Brasília-DF, ano 24, n. 36, p. 57-73, mar, 2006.

KOTLER, P; ROBERTO, E L. Marketing social: estratégias para alterar o comportamento público; Social marketing: strategies to change the public behavior. Campus, 1992. 
KOTLER, P., ZALTMAN, G. Social Marketing. Journal of Marketing, 35 (3): 3-12, Summer, 1971.

MOITA, F. ANDRADE, F. A indissociabilidade entre ensino, pesquisa e extensão: o caso do estágio de docência na pós-graduação. Revista Olhar de Professor, v. 16, n. 2, 2013.

NICHELS, W; WOOD, M. Marketing: relacionamento, qualidade, valor. Rio de janeiro: Livros Técnicos e Científicos, 1999.

PERNALETE, M e ORTEGA, M. Responsabilidad Social de la Universidad: retos y perspectivas. Buenos Aires: Paidós, 2010.

PUCCI, B. A. Indissociabilidade entre Ensino Pesquisa e Extensão. Impulso, Piracicaba, p. 33- 42, 1991.

RAYS, O. Ensino Pesquisa Extensão: notas para pensar a indissociabilidade. Cadernos de Educação Especial/Universidade Federal de Santa Maria. Departamento de Educação Especial/LAPEDOC. Edição: Nº 21, 2003.

RIBEIRO, R. A extensão universitária como fator da Responsabilidade Social Universitária. Revista Espaço Acadêmico. n. 128, janeiro, 2012.

TENÓRIO, F (org); colaboradores Fabiano Christian Pucci do Nascimento.(et al.)

Responsabilidade Social Empresarial: teoria e prática. Rio de Janeiro: Editora FGV, 2006.

VALLAEYS, F. O que significa responsabilidade social universitária? Estudos, v.24, n.36, 2006.

VAZ, G. Marketing Institucional: o mercado de idéias e imagens. São Paulo: Pioneira, 1999.

Revista Extensão em Foco, nº 17, Out./ Dez. (2018), p. 01 - 17. 